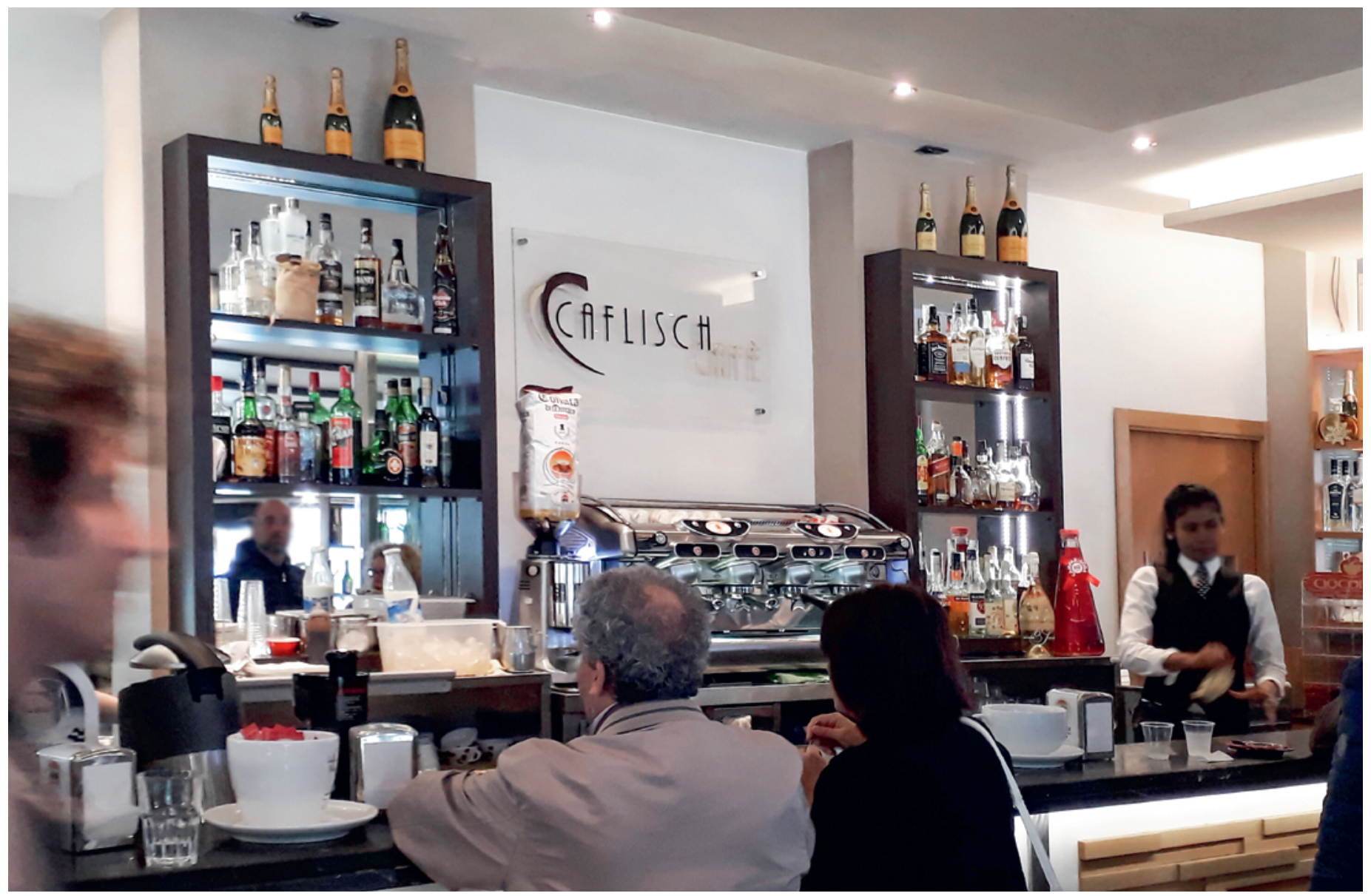

\title{
M wie Emigrieren und Immigrieren
}

\section{Dominik Heim}

PD Dr. med., Facharzt für Chirurgie, Mitglied FMH

«It's not that the coffee's bad; it's more that the people up here simply don't know what good coffee is or don't know how to make it», meint commissario Claudia Griffoni zu ihrem Kollegen, commissario Guido Brunetti [1]. Sie stammt halt aus Neapel, wo der Kaffee eben besser sein soll ist, er aber ist der einheimische Ermittler aus Venedig in den Romanen von der amerikanischen Schriftstellerin Donna Leon. Diese KaffeeKritik löst (musikalische) Erinnerungen aus. So, wie es im Jazz ist, das Thema ist gegeben, und der Rest ist freie Improvisation dazu: Da war doch diese $\mathrm{CD}$, «Caffè Caflisch» hiess sie [2] von Pippo Pollina, dem in der Schweiz lebenden Cantautore mit sizilianischen Wurzeln, und Linard Bardill, dem Barden aus Graubünden. Sie lehnt an die Geschichte von Christian Caflisch an, der als 15-jähriger Sohn einer bündnerischen Grossfamilie aus Trin nach Italien ausgewandert ist und nach Lehrjahren als Zuckerbäcker in
Neapel sein eigenes Caffè Caflisch in Palermo aufgemacht hat. Es gab auch andere Caflischs, zum Beispiel Esaias, der schon früher - in Neapel - als Luigi Caflisch mit grossem Erfolg die «Pasticceria, Confetture und Coloniali» an der Via Toledi gründete. Gut möglich also, dass Christian bei Luigi/ Esaias in die Lehre ging. Und so kommt meine belletristisch-musikalische Kaffee-Assoziation in Neapel zusammen.

Diese Kaffee-Kritik löst (musikalische) Erinnerungen aus.

Die Zuckerbäcker aus Graubünden, «ils pastiziers» in der romanischen Sprache, gingen im 19. Jahrhundert sehr häufig ins Ausland, häufig auch nach Italien. Und sie belegen mit ihren Lebensgeschichten, wie Emigration damals in der Schweiz ein häufiges Ereignis war. Glück war dabei nicht allen bestimmt: «Aber wie 
vielen ist das Glück günstig? Kann man sagen, dass von zehn Zuckerbäckerjungen einer reich wird?» [3] Christian Caflisch in Palermo und Esaias alias Luigi in Neapel war dieses Glück beschieden.

\section{Man sagt, dass auch Giuseppe Tomasi di Lampedusa hier seinen berühmten Familien- Roman «Il gattopardo»,geschrieben habe.}

Pippo Pollina verbrachte seine Zeit häufig in eben diesem damals berühmten "Caffè Caflisch" an der vornehmen Via Maqueda in Palermo. Man sagt, dass auch Giuseppe Tomasi di Lampedusa, hier seinen berühmten Familien-Roman «Il gattopardo», die Geschichte über den sizilianischen Aufstand gegen die Aristrokratie im 19. Jahrhundert, geschrieben habe (das Buch wurde verfilmt von Luchino Visconti, dem italienischen Regisseur, mit Claudia Cardinale in einer der Hauptrollen). Ein höchst amüsantes Detail zum Buch ist, dass renommierte Verlage diesen Roman abgelehnt haben und deshalb der linke Feltrinelli [4] ihn dann publizierte. Der Roman gilt heute als eines der wichtigsten Bücher Italiens.

Pollina, ursprünglich Jus-Student in Palermo, wanderte später - ohne Studienabschluss - aus Gründen der Korruption und der Mafia aus Sizilien aus und reiste als Cantautore durch Europa. In der Schweiz traf er Linard Bardill und zusammen schrieben sie Lieder über die Emigration und über die Heimat und veröffentlichten diese in "Caffè Caflisch»: «Siamo venuti da lontano armati di pane e pazienza con un biglietto nella mano ed un' idea nella credenza...» Beide Caflischs kehrten viel später wieder in die Schweiz zurück und starben zuhause in Graubünden. Das erfolgreiche Caffè im histori- schen Zentrum Palermos wurde geschlossen, in einem Aussenbezirk von Palermo gibt es noch das Caffè Caflisch (Abbildung), geführt von einer italienischen Familie. Die Dame an der Kasse konnte mir über die Vergangenheit keine Auskunft geben. Auch suchte ich vergebens im Feltrinelli, dem Kulturladen, an der Via Cavour in Palermo die CDs von Pippo Pollina. Ihn, den sizilianischen Cantautatore aus Palermo, kennt man in Palermo nicht. Und doch singt er auf «L'appartanenza» [5]: «Und heute komme ich manchmal heimlich, denn das Meer ruft und kennt keine Vernunft. Ich verzeihe dir, Sizilien und verlasse dich nie. Denn mein Herz gehört dir, jetzt und für immer» (übersetzt aus dem Italienischen von Christina Pollina Roos).

\section{Auch im schweizerischen Gesundheitswesen immigrieren heute viele, emigrieren tun wenige.}

Emigrieren, Immigrieren, das ist heute ein gängiges Phänomen. Auch im schweizerischen Gesundheitswesen immigrieren heute viele, emigrieren tun wenige. Weil es uns so gut geht? Das war aber eben nicht immer so! Wie haben wir das eigentlich geschafft?

\section{Bildnachweis}

Foto Dominik Heim

\section{Referenzen}

1 Leon D. «The temptation of forgiveness». William Heinemann Verlag; 2018.

2 Pollina P, Bardill L. «Caffè Caflisch», Jazz House Records, Freiburg D, 2008.

3 Der liberale Alpenbote, 29.01.1856, aus Geschichte der Alpen 2007/12

4 Heim D. G wie grand old man oder die vergangene Gegenwart. SAEZ 2015;96(4):123

5 Pippo Pollina: «L’appartanenza». Jazz House records, 2014 